\title{
Long-term results and complications following uvulopalatopharyngoplasty in 116 consecutive patients
}

Received: 21 June 2005/ Accepted: 16 September 2005/Published online: 19 May 2006

(C) Springer-Verlag 2006

\begin{abstract}
A modified uvulopalatopharyngoplasty (UPPP) was carried out between January 1992 and December 2003 at the ENT Department of the Inselspital in Bern in 146 patients with habitual or complicated rhonchopathy. The operation consisted of a classical tonsillectomy or residual tonsil resection and additional shortening of the uvula. The natural mucosal fold between the uvula and the upper pole of the tonsils was carefully preserved. A wide opening to the rhinopharynx was created by asymmetric suturing of the glossopalantine and pharyngopalatine arches. A retrospective questionnaire with regard to rhonchopathy, phases of apnea, daytime drowsiness, obstruction of nasal breathing, long-term complications and patient satisfaction was used to evaluate the short-term and longterm effectiveness of the modified UPPP as well as the incidence of adverse side effects. Complete postoperative courses were evaluated in 116 patients. Surgical complications were restricted to one case with postoperative hemorrhage. A velum insufficiency or postoperative rhinopharyngeal stenosis did not occur. Eighty-three patients $(72 \%)$ confirmed a persistent suppression or substantial improvement of the rhonchopathy. Disappearance or decrease of sleep apnea was confirmed in 12 $(63 \%)$ out of 19 postoperative polysomnographic follow-up investigations. Long-term complications occurred in a total of $27(23 \%)$ of 116 patients. They were confined to minor problems such as dryness of the mouth $(n=12)$, slight difficulty in swallowing $(n=7)$, discrete speech disturbances $(n=1)$, and slight pharyngeal dysesthesias $(n=7)$ with feeling of a lump in the throat and compulsive clearing of the throat. Eightyfive patients $(73 \%)$ reported that they were satisfied with the postoperative result even several years after the
\end{abstract}

\footnotetext{
C. Röösli · S. Schneider · R. Häusler ( $₫)$

Department of ENT, Head and Neck Surgery, Inselspital,

University of Bern, 3010 Bern, Switzerland

E-mail: rudolf.haeusler@insel.ch

Tel.: + 41-31-6322921

Fax: + 41-31-6328808
}

operation. Looking back, 31 patients $(27 \%)$ would no longer have the operation performed. The inadequate result of the rhonchopathy was specified as the reason by 21 patients. Ten patients had unpleasant memories of the operation because of intensive postoperative pain. Snoring and apneic phases are suppressed or improved by non-traumatic UPPP in the majority of patients. This effect persisted even years after the operation.

Keywords Snoring - Sleep apnea syndrome · Complications $\cdot$ Follow-up studies $\cdot$ Polysomnography

\section{Introduction}

Occasional snoring occurs in everyone and is of no pathological significance. Frequent and loud snoring combined with nocturnal apnea and excessive daytime sleepiness are the symptoms of habitual or complicated rhonchopathy and obstructive sleep apnea syndrome (OSAS). If these are not diagnosed or remain untreated, serious medical [1-3] and partner relationship [4] problems may result. The prevalence of habitual rhonchopathy is up to $24 \%$ of the adult male and up to $14 \%$ of the adult female population [5]. In the past 25 years, two methods for treatment had been developed at the same time and independently. The surgical treatment of the soft palate with uvulopalatopharyngoplasty (UPPP) [6] was initiated in 1981 and further developed over the years. A noninvasive therapy option entailing continuous positive airway pressure (cPAP) during the night was introduced in 1981 [7]. Although cPAP has been shown to be effective in improving both daytime sleepiness and nocturnal desaturations its therapeutic use is seriously limited by low long-term compliance [8]. Therefore, the demand for a definitive surgical treatment of rhonchopathy has still not been met.

The present study focuses on surgical treatment. It investigates the short-term and long-term success rate during the last 12 years in treating rhonchopathy and 
obstructive sleep apnea syndrome in the ENT Department of the Inselspital University Hospital in Bern using modified UPPP.

\section{Materials and methods}

\section{Subjective evaluation}

This retrospective study analyses the results of all patients who underwent UPPP for treatment of rhonchopathy between January 1992 and December 2003. The patients and their partners were evaluated by telephone or on a face-to-face basis with regard to changes in snoring, apnea phases, daytime drowsiness, impediments to nasal breathing and body weight using a specially designed questionnaire. The occurrence and extent of postoperative complications were appraised and patients were asked whether they would decide again in favor of surgical treatment.

The preoperative data with regard to history, status on admission and clinical follow-up were compiled from the patient records, surgical reports and anesthesia files.

\section{Uvulopalatopharyngoplasty}

The operation was performed according to the procedure described by Fujita et al. [9] with slight modifications. Tonsillectomy was performed at the same time in those patients who had not undergone this procedure previously. The uvula was shortened whenever necessary. The natural mucosal fold between the uvula and the upper pole of the tonsils was strictly preserved. A wide opening towards the rhinopharynx was created by asymmetric suturing of the anterior and posterior pillars of fauces ${ }^{1}$ (Fig. 1).

\section{Polysomnography}

Polysomnography was carried out as an additional investigation in a total of 48 patients $(41 \%)$, preoperatively in 38 patients and postoperatively in 19 patients. The measurement was carried out in accordance with the usual standards [9].

\section{Statistical analysis}

Significance was tested on the basis of the $F$-distribution test, the chi square $\left(\chi^{2}\right)$ test parameter and the Spearman rank order correlation coefficient. The level of significance was set at a probability of error of $P \leq 0.05$.

\footnotetext{
${ }^{1}$ In two earlier cases, the technique of modified UPPP was not exactly adhered to. The mucosa between the upper pole of the tonsils and the uvula was resected in these cases. Both patients described a persistent rhonchopathy. Nevertheless, they were included in the following evaluation.
}

\section{Results}

General evaluation

The data from $116(79.5 \%)$ of the 146 patients could be evaluated. Ninety-nine were male $(85 \%)$ and 17 female $(15 \%)$. Thirty patients could not be contacted because they had moved abroad or because they had died for reasons unconnected with the rhonchopathy.

The mean period of observation was 6.4 years (range, 1.5-12 year). The average age was 50 years (range, 21-70 year).

Almost all patients had a large, long, fleshy thickened uvula. There was typically a strikingly narrow isthmus of fauces and confined conditions in the oropharynx (Figs. 2, 3).

\section{Outcome evaluation of rhonchopathy and OSAS}

The postoperative improvements of the preoperative symptoms are summarized in Table 1. Subjective improvement elimination of rhonchopathy was reported in 83 patients $(72 \%)$. Sleep apnea could be eliminated or reduced in $45(72 \%)$ of 63 patients with preoperative apnea. Excessive daytime sleepiness could be lastingly reduced in $30(63 \%)$ of the 48 patients with preoperative symptoms. Improved nasal breathing was described by $27(65 \%)$ of the 42 patients who suffered preoperatively from impeded nasal breathing.

Neither the average long-term postoperative increase in weight from 84.47 to $85.53 \mathrm{~kg}(P=0.89)$ nor the rise of BMI from 27.63 to $28.05 \mathrm{~kg} / \mathrm{m}^{2}(P=0.94)$ turned out to be significant in affecting the result of the operation although weight is a factor evincing a trend (Table 2).

The polysomnography carried out preoperatively in 38 patients led to diagnosis of an OSAS in 28 patients (mild: $n=7$, moderately severe: $n=13$, severe: $n=8$ ). In nine sleep registrations taken postoperatively in patients with known OSAS, three patients $(33 \%)$ no longer had any manifest OSAS. One patient showed a marked reduction of the apnea index. Of the remaining five patients in whom no alterations of the apnea index could be established objectively, three were nevertheless cured with regard to rhonchopathy. This means that despite disappearance of the rhonchopathy, sleep apnea was still present in the three patients as "silent" sleep apnea. The rhonchopathy remained unchanged in two patients.

Acute postoperative adverse effects

Only one surgical complication was seen immediately post-operatively, which was a postoperative hemorrhage necessitating revision surgery. There was no mortality connected with UPPP in our series. 
Fig. 1 Schematic

representation of the non-

traumatic surgical technique

used in Bern (modified

according to Fujita et al. [6])
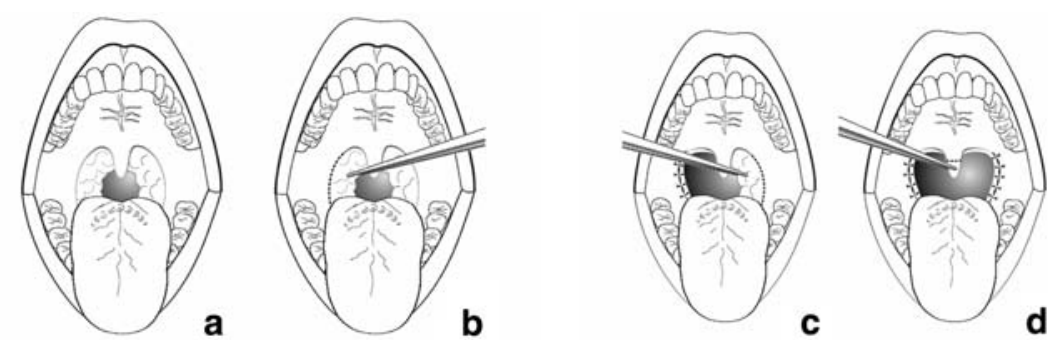

d

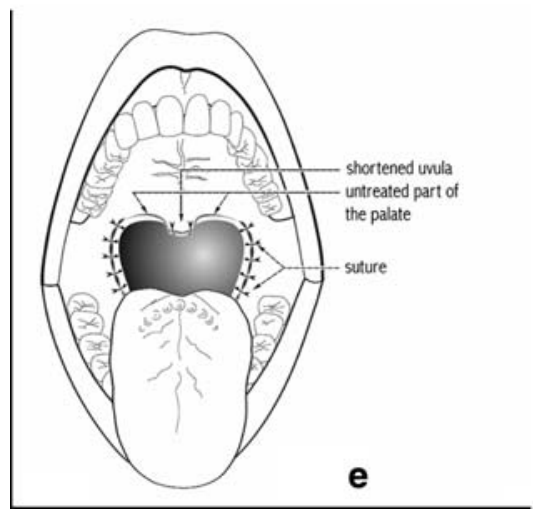

Chronic postoperative adverse effects

Eighty-nine $(77 \%)$ of the 116 patients surveyed did not have any troublesome postoperative symptoms. In 27 patients $(23 \%)$, mild permanent or intermittent postoperative complications were designated as disagreeable. Dryness of the mouth (12 patients), speech disorders (1 patient) and pharyngeal dysesthesias (14 patients) with feeling of a lump in the throat, compulsive clearing of the throat and slight difficulty in swallowing were found.

General evaluation of the UPPP results by the patients

Eighty-five patients $(73 \%)$ stated that they would have the operation again even after several years had elapsed.

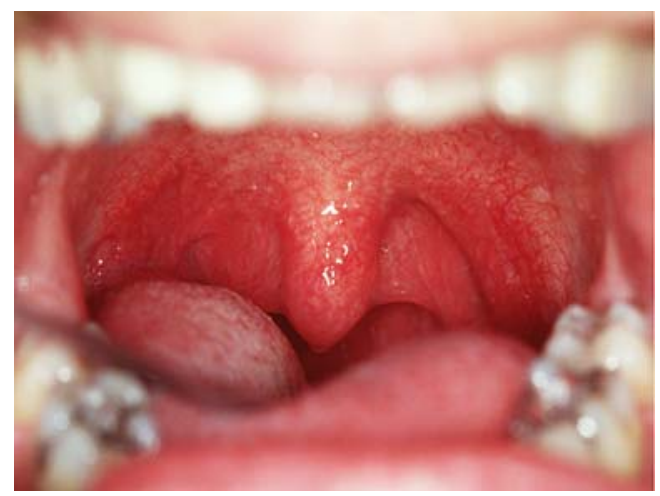

Fig. 2 Typical findings in the soft palate in patients with OSAS: uvular hyperplasia, depressed pillars of fauces with an extremely narrow transition into the rhinopharynx
The remaining 31 patients $(27 \%)$ would not do so. Twenty-one of these 31 patients $(18 \%)$ specified an unsatisfactory result with respect to their snoring as the reason of their reservations and 10 of these 31 patients $(9 \%)$ reported the pronounced pain in the postoperative convalescence despite a good result with regard to their rhonchopathy.

\section{Discussion}

The age distribution of the patient population in this retrospective long-term evaluation after modified UPPP in patients with habitual or complicated rhonchopathy does not reflect the increasing prevalence of rhonchopathy with age $[10,11]$. Younger patients asked for therapy more often than older patients. Self-selection and referral bias must be assumed to be the reason. Male sex is a major risk factor for rhonchopathy, as reported

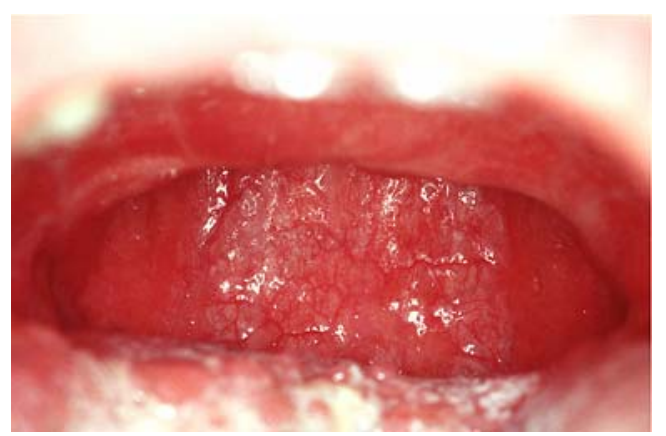

Fig. 3 The postoperative site with wide pharyngeal opening 
Table 1 Description of postoperative changes of preoperative symptoms

\begin{tabular}{|c|c|c|c|c|c|c|}
\hline \multirow[t]{2}{*}{$\begin{array}{l}\text { Preoperative } \\
\text { symptoms }\end{array}$} & \multicolumn{2}{|c|}{ Improvement } & \multicolumn{2}{|c|}{ No change } & \multicolumn{2}{|c|}{$\begin{array}{l}\text { Getting } \\
\text { worse }\end{array}$} \\
\hline & $N$ & Percent & $N$ & Percent & $N$ & Percent \\
\hline $\begin{array}{l}\text { Rhonchopathy } \\
(n=116)\end{array}$ & 83 & 72 & 28 & 24 & 5 & 4 \\
\hline $\begin{array}{l}\text { Sleep apnea } \\
(n=63)\end{array}$ & 45 & 72 & 16 & 25 & 2 & 3 \\
\hline $\begin{array}{l}\text { Daytime } \\
\text { drowsiness } \\
(n=48)\end{array}$ & 30 & 63 & 17 & 35 & 1 & 2 \\
\hline $\begin{array}{l}\text { Obstruction } \\
\text { of nasal } \\
\text { breathing } \\
(n=42)\end{array}$ & 27 & 65 & 14 & 33 & 1 & 2 \\
\hline
\end{tabular}

by Walker et al. [12]. This can be explained by the higher prevalence of habitual rhonchopathy in men.

The long-term success rate of UPPP is reported in the literature [13-15] as ranging from 50 to $81 \%$. The results in our series (lasting improvement or elimination of rhonchopathy in $72 \%$ ) tend to be in the upper range of those reported in the literature. Hessel et al. [9] found a subjective improvement of the rhonchopathy in 111 $(81 \%)$ of the 136 patients investigated. However, the period of observation (3-5 months) was much shorter compared to the present study.

The individual improvement of sleep apnea in a total of $72 \%$ of the patients (elimination in $30 \%$, marked improvement in $42 \%$ ) is greater than that reported by others $[15,16]$.

Excessive day-time sleepiness could successfully be treated in $63 \%$ of the patients in our series. This number is in the range reported by others [17].

A reduction in weight is a factor evincing a trend $(P=0.37)$ for rhonchopathy to decrease in our series, but this effect is not statistically significant. Literature data on this is contradictory: Larson et al. [18], Verse et al. [19] and Hicklin et al. [17], but not Boot et al. [20] reported an effect of body weight on the results of UPPP. It remains controversial whether the decrease in

Table 2 Correlation between change of weight and change of snoring

\begin{tabular}{|c|c|c|c|c|c|c|}
\hline \multirow[t]{2}{*}{ Snoring } & \multicolumn{2}{|c|}{$\begin{array}{l}\text { Constant } \\
\text { weight } \\
(n=48)\end{array}$} & \multicolumn{2}{|l|}{$\begin{array}{l}\text { Decrease } \\
\text { in weight } \\
(n=29)\end{array}$} & \multicolumn{2}{|l|}{$\begin{array}{l}\text { Increase } \\
\text { in weight } \\
(n=39)\end{array}$} \\
\hline & Number & Percent & Number & Percent & Number & Percent \\
\hline Decrease & 36 & 75 & 23 & 79 & 24 & 61.5 \\
\hline Constant & 10 & 21 & 6 & 21 & 12 & 31 \\
\hline Increase & 2 & 4 & 0 & - & 3 & 7.5 \\
\hline Total & 48 & 100 & 29 & 100 & 39 & 100 \\
\hline
\end{tabular}

There is no correlation between change of weight and change of snoring according to Spearman rank order correlation coefficient $(P=0.37)$ weight results because of normalization of sleep, daytime sleepiness and appetite or whether the decrease in weight causes less rhonchopathy independently of the UPPP.

An elimination or reduction of sleep apnea was confirmed in $12(63 \%)$ out of 19 postoperative polysomnographic follow-up investigations.

Postoperative polysomnographies could only be realized in a limited number of patients mainly for economic or insurance reasons. Therefore, nine patients had a polysomnography pre- and postoperatively. This small number of patients is not representative for the study population. Interestingly, in three patients who stopped snoring postoperatively, the sleep apnea remained unchanged. Silent apneas after surgery for snoring are also described by others [21].

With respect to acute surgical complications, there was one single case of hemorrhage which could be successfully staunched in the operating theater. According to Haavisto et al. [22], hemorrhages can occur postoperatively in up to $14 \%$ of the patients. Stenoses in the nasopharyngeal region are described as complications to be feared after UPPP [23]. In our series, stenoses did not occur in any of the patients treated by means of our modified UPPP technique with preservation of the mucosal fold between uvula and the upper pole of the tonsils. There was no mortality connected with UPPP in our series. Several deaths after UPPP have however been described in the literature [14, 22, 24, 25]. They were caused either by an acute obstruction of the upper airways or by cataclysmic hemorrhages.

Long-term complications several years after the intervention were reported by 27 patients $(23 \%)$. They were described as being mild. The majority of the 27 patients did not report any of these complications spontaneously during the telephone questionnaire, but mentioned them only in response to explicit questioning.

Pharyngeal dryness was the most frequent long-term side effect mentioned in our series. It occurred in $60 \%$ of the patients whose snoring did not improve and may be connected to breathing through the mouth, which is usual in snoring.

In the body of literature Grontved et al. [26] surveyed 69 patients an average of 27 months after the operation by means of a questionnaire sent out to them. Forty-two percent suffered from complications, which were described as disagreeable by $3 \%$. Regurgitation $(13 \%)$, hypersecretion $(10 \%)$ and disorders of swallowing $(9 \%)$ were reported most frequently. Hicklin et al. [17] investigated the long-term complications by asking a general question without specifically inquiring about particular symptoms. There were complaints about long-term symptoms from $38 \%$ of the patients. Haavisto et al. [22] described dryness of the mouth in $31 \%$ of patients, velopharyngeal insufficiency (VPI) in $24 \%$ and swallowing difficulties in $10 \% 1$ year after the operation.

We consider that preservation of the natural mucosal fold between the tonsils and the uvula might be an important factor for the intervention to be successful 
and to avoid postoperative complications. An incision of the soft palate on both sides of the uvula resulted in unsatisfactory results in single early cases so this method was abandoned. The gain in space in the pharynx attained by UPPP leads to a change in the flow conditions of air. As a consequence, rhonchopathy and its associated symptoms can be permanently eliminated or substantially decreased in the majority of cases.

Patient satisfaction of $75 \%$ in our series is within the upper range of $49 \%$ [17] to $86 \%$ [26] reported in the literature. Besides the inadequate reduction of snoring and postoperative pain, Hicklin et al. [17] reported postoperative complications as a particular reason for low patient satisfaction [49\%]. This reason was not mentioned by any patient in our study. Grontved et al. [26] also found significantly more complications and persistence of snoring in the patients who were generally dissatisfied after the operation (14\%).

\section{Conclusions}

The technique of modified UPPP with preservation of the mucosal fold between the uvula and the upper pole of the tonsils used at the ENT Department at the Inselspital University Hospital in Bern leads to a sustained suppression or major alleviation of rhonchopathy not only in the short-term but also in the long-term course with a relatively high proportion of satisfied patients. For the majority, this entails an improvement in the quality of life for the patients themselves and for their partners. The modified UPPP has a good success rate with a minimal incidence of surgical complications. The long-term adverse effects such as dryness of the mouth, speech disorders and pharyngeal dysesthesias were rated as rather minor.

\section{References}

1. Research NcoSD (1994) National Center on Sleep Research, National Heart, Lung and Blood Institute, National Institutes of Health

2. Guilleminault C, Stoohs R, Clerk A, Simmons J, Labanowski M (1992) From obstructive sleep apnea syndrome to upper airway resistance syndrome: consistency of daytime sleepiness. Sleep 15(6 Suppl):S13-S16

3. Waller PC, Bhopal RS (1989) Is snoring a cause of vascular disease? An epidemiological review. Lancet 1(8630):143-146

4. Armstrong MW, Wallace CL, Marais J (1999) The effect of surgery upon the quality of life in snoring patients and their partners: a between-subjects case-controlled trial. Clin Otolaryngol 24(6):510-522

5. Woodhead CJ, Davies JE, Allen MB (1991) Obstructive sleep apnoea in adults presenting with snoring. Clin Otolaryngol 16(4):401-405

6. Fujita S, Conway W, Zorick F, Roth T (1981) Surgical correction of anatomic abnormalities in obstructive sleep apnea syndrome: uvulopalatopharyngoplasty. Otolaryngol Head Neck Surg 89(6):923-934
7. Sullivan CE, Issa FG, Berthon-Jones M, Eves L (1981) Reversal of obstructive sleep apnoea by continuous positive airway pressure applied through the nares. Lancet 1(8225):862865

8. McArdle N, Devereux G, Heidarnejad H, Engleman HM, Mackay TW, Douglas NJ (1999) Long-term use of CPAP therapy for sleep apnea/hypopnea syndrome. Am J Respir Crit Care Med 159(4 Pt 1):1108-1114

9. Sivan Y (2005) Normal polysomnography in children and adolescents. Chest 127(3):1080

10. Ancoli-Israel S (1989) Epidemiology of sleep disorders. Clin Geriatr Med 5(2):347-362

11. Schmidt-Nowara WW (1990) Epidemiology of sleep apnea. In: Guilleminault C (eds) Obstructive sleep apnea syndrome: clinical research and treatment. Raven Press, New York

12. Walker RP, Durazo-Arvizu R, Wachter B, Gopalsami C (2001) Preoperative differences between male and female patients with sleep apnea. Laryngoscope 111(9):1501-1505

13. Sher AE, Schechtman KB, Piccirillo JF (1996) The efficacy of surgical modifications of the upper airway in adults with obstructive sleep apnea syndrome. Sleep 19(2):156-177

14. Pepin JL, Veale D, Mayer P, Bettega G, Wuyam B, Levy P (1996) Critical analysis of the results of surgery in the treatment of snoring, upper airway resistance syndrome (UARS), and obstructive sleep apnea (OSA). Sleep 19(9 Suppl):S90-S100

15. Hessel NS, de Vries N (2003) Results of uvulopalatopharyngoplasty after diagnostic workup with polysomnography and sleep endoscopy: a report of 136 snoring patients. Eur Arch Otorhinolaryngol 260(2):91-95

16. Thalhofer S, Dorow P, Jahnke V, Kuhler U, Meissner P (1995) Polysomnographic results before and after uvulopalatopharyngoplasty (UPPP). Pneumologie 49(Suppl 1):180-182

17. Hicklin LA, Tostevin P, Dasan S (2000) Retrospective survey of long-term results and patient satisfaction with uvulopalatopharyngoplasty for snoring. J Laryngol Otol 114(9):675-681

18. Larsson LH, Carlsson-Nordlander B, Svanborg E (1994) Fouryear follow-up after uvulopalatopharyngoplasty in 50 unselected patients with obstructive sleep apnea syndrome. Laryngoscope 104(11 Pt 1):1362-1368

19. Verse T, Baisch A, Hormann K (2004) Multi-level surgery for obstructive sleep apnea. Preliminary objective results. Laryngorhinootologie 83(8):516-522

20. Boot H, van Wegen R, Poublon RM, Bogaard JM, Schmitz PI, van der Meche FG (2000) Long-term results of uvulopalatopharyngoplasty for obstructive sleep apnea syndrome. Laryngoscope 110(3 Pt 1):469-475

21. Carlsson-Nordlander B, Larsson H, Svanborg E (1991) Warning against silent apneas after surgery for snoring. Lakartidningen 88(12):1063-1065

22. Haavisto L, Suonpaa J (1994) Complications of uvulopalatopharyngoplasty. Clin Otolaryngol 19(3):243-247

23. DeAngelo A, Mysliwiec V (2004) Resolution of severe sleepdisordered breathing with a nasopharyngeal obturator in 2 cases of nasopharyngeal stenosis complicating uvulopalatopharyngoplasty. Sleep Breath 8(1):49-55

24. Esclamado RM, Glenn MG, McCulloch TM, Cummings CW (1989) Perioperative complications and risk factors in the surgical treatment of obstructive sleep apnea syndrome. Laryngoscope 99(11):1125-1129

25. Kezirian EJ, Weaver EM, Yueh B, Deyo RA, Khuri SF, Daley $\mathrm{J}$, et al (2004) Incidence of serious complications after uvulopalatopharyngoplasty. Laryngoscope 114(3):450-453

26. Grontved AM, Karup P (2000) Complaints and satisfaction after uvulopalatopharyngoplasty. Acta Otolaryngol Suppl 543:190-192 